\title{
Nutritional assessment of patients with end-stage renal disease using the MNA scale
}

\author{
Łukasz Rogowski ${ }^{1, A-D}$, Mariusz Kusztal ${ }^{2, C, E}$, Tomasz Gołębiowski2,B,C, Katarzyna Bulińska, 3,B,C, \\ Agnieszka Zembroń-Łacny ${ }^{4, E}$, Joanna Wyka ${ }^{5, E}$, Marian Klinger ${ }^{2, E, F}$, Marek Woźniewski ${ }^{3, E, F}$, Wioletta Dziubek ${ }^{3, C-F}$ \\ ${ }^{1}$ Nonpublic Medical College, Wrocław, Poland \\ 2 Department and Clinic of Nephrology and Transplantation Medicine, Faculty of Medicine, Wroclaw Medical University, Poland \\ ${ }^{3}$ Department of Physiotherapy, University School of Physical Education, Wrocław, Poland \\ ${ }^{4}$ Faculty of Medicine and Health Sciences, University of Zielona Góra, Poland \\ ${ }^{5}$ Department of Human Nutrition, Faculty of Food Science, University of Environmental and Life Sciences, Wrocław, Poland \\ A - research concept and design; $\mathrm{B}$ - collection and/or assembly of data; $\mathrm{C}$ - data analysis and interpretation; \\ $D$ - writing the article; $E$ - critical revision of the article; $F$ - final approval of the article
}

Address for correspondence

Mariusz Kusztal

E-mail:mariok@02.pl

\section{Funding sources}

The study was supported by a research grant from the National Science Centre of Poland (No. 2011/03/B/NZ7/01764, grant title: "The effects of exercise training on muscle regeneration activity in hemodialysis patients"; to WD). The funding agency had no role in the study design, collection, analysis, and interpretation of data, or the decision to submit this original work for publication.

\section{Conflict of interest}

None declared

\section{Acknowledgements}

The authors thank the nursing and medical staff at the Dialysis Center at the University Clinical Hospital in Wrockaw for their friendly support.

Received on January 9, 2017 Reviewed on February 15, 2017 Accepted on June 30, 2017

\begin{abstract}
Background. Patient malnutrition is a significant problem in the process of rehabilitation and treatment. One of the tools that can reveal the risk of malnutrition is a series of standardized nutritional questionnaires.

Objectives. The aim of the study was to assess the nutritional status of patients with end-stage renal disease (ESRD) by means of the minimal nutritional assessment (MNA) scale.

Material and methods. The study group included respondents suffering from ESRD who were patients of the Dialysis Center at the Clinic of Nephrology and Transplantation Medicine at the University Clinical Hospital in Wrocław. The study was conducted in 47 dialysis patients (22 women and 25 men), mean age $69.68 \pm 8.95$ years. A standardized MNA scale was used to evaluate the nutritional status of the patients.
\end{abstract}

Results. In the study group, women had a significantly lower score on the MNA scale than men (23.95 vs 25.26 points). Using the MNA scale, the risk of malnutrition was found in 13 patients, while malnutrition was found in 1 patient. Among females, the mean body mass index (BMI) was 27.28, and it was significantly correlated with the MNA score. In males, the mean BMI was 29.61, but it did not correlate with the MNA score. The time spent undergoing renal replacement therapy was 7.63 years for women and 7.24 years for men. This correlated significantly with the MNA score only in the case of men. Significant correlations were established between eating habits and MNA scores in both groups.

Conclusions. The results obtained using the MNA scale showed a significant risk of malnutrition in patients with ESRD. In women only, a low score on the MNA scale significantly correlated with the BMI. The time of renal replacement therapy had a significant impact on the MNA scale only in the case of men. An influence of comorbidities on the MNA scores recorded by men and women was not observed. Major health incidents and other stressful situations significantly affected the nutritional status in men.

Key words: nutritional status, chronic kidney failure, hemodialysis patients, minimal nutritional assessment

DOI

10.17219/acem/75604

Copyright

Copyright by Author(s)

This is an article distributed under the terms of the

Creative Commons Attribution Non-Commercial License

(http://creativecommons.org/licenses/by-nc-nd/4.0/) 


\section{Introduction}

Kidney failure is an increasingly common disorder, affecting $11 \%$ of the world adult population. ${ }^{1}$ It was estimated that in 2010 there were about 2 million patients worldwide in the end stage of this disease, i.e., being treated with renal replacement therapy. This number is expected to grow by as much as $7 \%$ per year. ${ }^{2}$ It is estimated that there are 4 million patients with chronic kidney disease (CKD) in Poland, of whom 17,000 are being treated with renal replacement therapy. ${ }^{3}$ For decades, it has been believed that the main cause of kidney disease was glomerulonephritis. However, the rapidly increasing number of cases has compelled the scientific community to re-examine the causes of kidney failure. Several studies have shown a strong correlation between the occurrence of metabolic disorders, such as diabetes and hypertension, and the development of kidney diseases or nephropathy. Knowing the main causes of kidney failure, it is hard not to notice that 2 of the 3 risk factors have a close relationship with the wider phenomenon known as the "diseases of civilization". A very important problem that often occurs and substantially affects the health of patients with CKD is malnutrition. ${ }^{4-6}$ Extensive studies of patients with CKD in the Modification of Diet in Renal Disease (MDRD) project recorded weight loss in $21 \%$ of patients during the 14 months of observations. ${ }^{7}$ Patients treated with long-term renal replacement therapy who have received a diagnosis of malnutrition are at a particularly increased risk of complications, and even death, during dialysis. ${ }^{8}$ The problem of poor nutritional status of patients with CKD is even perceived as the main cause of poor clinical prognosis and mortality. ${ }^{9-12} \mathrm{Nu}$ merous studies assessing the nutritional status of patients with CKD, using methods such as anthropometric assessments and biochemical evaluation, have shown a positive correlation with mortality. ${ }^{4,5,13,14}$

The causes of protein-energy malnutrition (PEM) are complex, resulting both from kidney diseases and concomitant diseases. The patients suffer from a general catabolic state, uremia, hormonal imbalance, lipid disorders, general disorders of the metabolism, and increased activity of pro-inflammatory cytokines. The problem of impaired sense of taste and suppression of appetite in patients with CKD is also not without significance and may also be psychological in nature, e.g., cause stress or depression. ${ }^{5,15,16}$ The dialysis mechanism itself, in which blood is filtered through a dialyzer, is a heavy burden that could also contribute to malnutrition. The dialysis initiates protein catabolism, impairing the protein synthesis. ${ }^{17,18}$ The key inducers of malnutrition are 2 factors: metabolic acidosis (MA) and the insufficient supply of nutrients. Unfortunately, MA is an inherent complication of kidney disease and its extent is dependent on the severity of renal failure. ${ }^{16}$ Metabolic acidosis leads to a state of malnutrition, initiating the breakdown of proteins and the oxidation of amino acids, loss of muscle mass, inflammation, and increased mortality. 5,19 Studies have shown that MA leads to a negative nitrogen balance, also reducing the level of albumins. ${ }^{20,21}$

A very important factor that may influence the nutritional status are the dietary restrictions undertaken by the patients. In the course of the diagnosis of kidney disease, as well as diseases that initiate it (diabetes, high blood pressure), patients are shown dietary recommendations that can positively affect the disease process. Patients with CKD are recommended to control the supply of protein and phosphorus. It has been shown that reduced protein intake can prolong the time taken for the disease to evolve into full kidney failure. In addition, a reduced supply of proteins and phosphorus allows for a better control of MA and the electrolyte equilibrium. ${ }^{10,18,22}$ Also, in the case of concomitant diseases, such as diabetes, hypertension and cardiovascular diseases, one strategy for supporting treatment is to modify the eating habits, in particular by strictly controlling the quality of energy substrates. Patients with end-stage renal disease (ESRD) no longer have to limit their protein intake (recommendations for healthy subjects); however, their restrictions include limiting the supply of phosphorus. ${ }^{10}$ The supply of carbohydrates and fats should be sufficiently high, taking into account physical activity and comorbidities. ${ }^{10}$ However, patients without ad hoc supervision by medical personnel or dieticians often cannot balance their diets sufficiently, which can in turn lead to an inadequate supply of nutrients and, eventually, PEM. 5,7,10,11

A useful tool for the preliminary assessment of the nutritional status of patients is the use of standardized questionnaires evaluating nourishment levels. Such surveys are easy and quick to complete, do not require any special equipment, and can therefore be used by medical personnel and dieticians. ${ }^{23}$ If the result is indicative of a "nutritional risk", more accurate (more expensive) methods of assessing nutritional status, e.g., anthropometric, biochemical or image-based assessments, namely, magnetic resonance imaging (MRI) and dual energy X-ray absorptiometry (DXA), can be employed.

In view of the very few reports on the use of minimal nutritional assessment (MNA) scale with stable hemodialysis outpatients, the aim o the study was to assess the nutritional status of patients with ESRD in a chronic hemodialysis therapy program. Secondary research aims were to assess the correlation of MNA scores with body mass index (BMI), the duration of dialysis therapy, and their relationship with the eating habits of ESRD patients, if any.

\section{Materials and methods}

The study group included patients over 60 years of age suffering from ESRD, recruited from the dialysis center of the Clinic of Nephrology and Transplantation Medicine at the Wroclaw Medical University and the International Dialysis Centre in Wrocław, Poland. 
All patients were informed about the purpose of the questionnaire and signed written informed consent to participate in the study. Inclusion criteria were: a diagnosed CKD, hemodialysis treatment for at least 6 months and age $>60$ years. Exclusion criteria were: kidney transplant and lack of consent to participate in research.

In order to evaluate the nutritional status of the patients, a standardized full version of MNA scale was used. The MNA scale is a simple nutrition screening and assessment tool, designed to determine the possibility of malnutrition. It was designed mainly for monitoring geriatric patients and, since the majority of CKD patients are chronically ill people over the age of 60 (mean age 69.68 years), the MNA scale was preferred as the most suitable option. An important feature of the MNA scale is that some of the questions are not related to anthropometric characteristics, which (according to present authors) may help in the case of patients with ESRD. These patients usually undergo hemodialysis for $4 \mathrm{~h} 3$ times a week; just before the dialysis they are weighed to determine the increase in the volume of fluid since the last dialysis (the water to be removed during dialysis). With this in mind, the personnel of the dialysis center use the so-called "dry body-weight" - the weight of the body after dialysis with no adverse symptoms (cramps, hypotonia or dizzin ess). This clinically defined dry body-weight may, therefore, change depending on the body's state of catabolism/anabolism and has a close relationship with appetite.

The MNA scale is characterized by high sensitivity and specificity. ${ }^{24,25}$ Compared with BMI, it has a higher sensitivity for identifying the states of malnutrition. ${ }^{26} \mathrm{~A}$ great advantage of MNA is its general availability and ease of use (quick diagnosis); therefore, it can be widely used in most healthcare facilities.

The results of the study were statistically analyzed using the STATISTICA v. 12 package (StatSoft, Tulsa, USA). Means and standard deviations (SDs) were determined as basic descriptive statistics. The normality of distributions was ascertained using the Shapiro-Wilk test. When examining differences in the distribution of variables between selected groups of men and women, Student's t-test for independent samples was used when the examined variable had a normal distribution. The exception was the comparison of test results, which did not meet the assumptions of a normal distribution. In this case the MannWhitney U test was used. Correlations were evaluated using Spearman's nonparametric rank-order correlation coefficient (p). The statistical significance was determined at a critical level of $\alpha=0.05$.

\section{Results}

In both outpatient dialysis centers, the initial inclusion criteria were met by 80 people. During the study, the group was reduced because of a transplant ( 2 patients), lack of consent to complete the questionnaire (22 patients) and incorrectly filled questionnaire (9 patients).

Finally, a total of 47 patients remained to the end of the research project; their mean age was $69.68 \pm 8.95$ years, 22 were female and 25 were male. Anthropometric measurements such as body mass and height were obtained, after which BMI values were calculated. Table 1 displays the patients' characteristics.

Table 1. Patient's characteristics

\begin{tabular}{|l|c|c|l|}
\multicolumn{1}{|c|}{ Variable } & \multicolumn{1}{|c|}{$\begin{array}{c}\text { Females } \\
(\mathrm{n}=22)\end{array}$} & $\begin{array}{c}\text { Males } \\
(\mathrm{n}=25)\end{array}$ & p-value \\
\hline Age [years] & $67.22 \pm 8.72$ & $71.84 \pm 8.75$ & 0.08 \\
\hline Body mass [kg] & $67.46 \pm 18.81$ & $85.22 \pm 12.45$ & 0.0003 \\
\hline Body height [cm] & $156.86 \pm 6.65$ & $169.68 \pm 6.41$ & $<0.00001$ \\
\hline Waist circumference [cm] & $93.11 \pm 15.34$ & $104.94 \pm 11.98$ & 0.004 \\
\hline Hip circumference [cm] & $100.27 \pm 13.04$ & $99.12 \pm 5.39$ & 0.7 \\
\hline Dialysis [years] & $7.6 \pm 4.04$ & $7.24 \pm 4.49$ & 0.75 \\
\hline Comorbidities [n] & $2.63 \pm 1.36$ & $3.3 \pm 1.24$ & 0.09 \\
\hline
\end{tabular}

The median MNA score was 25 (interquartile range [IQR] was 24-26,5) for females and 26,5 (IQR 23,5-28) for males. The mean MNA scores for both genders are shown in Fig. 1.

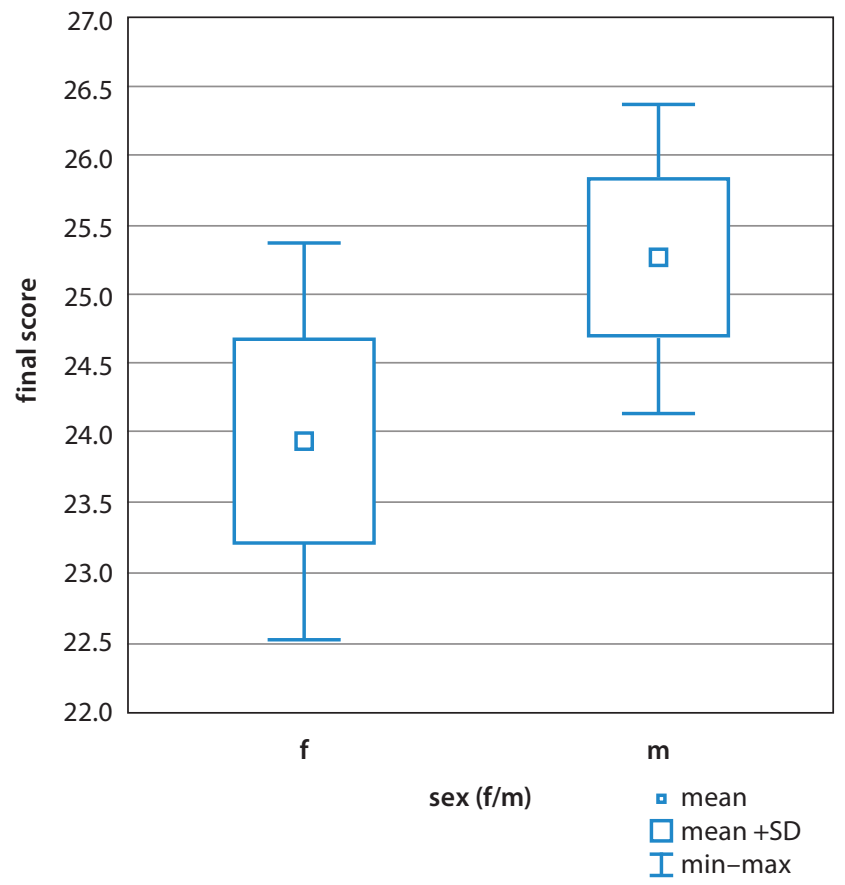

Fig. 1. Mean values of final minimal nutritional assessment (MNA) scores for women and men

Men had a higher mean value of BMI, and a lower SD (4.11). Women showed lower BMI values, while the SD was higher (6.65). It can be concluded that the female group exhibited fewer problems with overweight, while at the same time their body mass was more variable. 
Table 2 displays the correlations between MNA scores and anthropometric indices: BMI and number of years of renal replacement therapy. The final scores of the MNA scale demonstrated a significant positive correlation with body mass and BMI scores only in the case of women. An association with the duration of renal replacement therapy and the final MNA scores was demonstrated only in males (Table 2).

Table 2. Spearman's rank correlation coefficients ( $p$ ) of the final minimal nutritional assessment (MNA) scores with anthropometric indicators, body mass index (BMI) and the number of years of renal replacement therapy

\begin{tabular}{|l|c|c|}
\multicolumn{1}{|c|}{ Variable } & $\begin{array}{c}\text { MNA score } \\
\text { for females }(\boldsymbol{n}=22)\end{array}$ & $\begin{array}{c}\text { MNA score } \\
\text { for males }(\boldsymbol{n}=25)\end{array}$ \\
\hline Body mass $[\mathrm{kg}]$ & $0.64(p<0.05)$ & $0.007(p>0.05)$ \\
\hline BMI index & $0.62(p<0.05)$ & $0.18(p>0.05)$ \\
\hline Dialysis vintage [years] & $-0.32(p>0.05)$ & $-0.53(p<0.05)$ \\
\hline
\end{tabular}

In men, a clear correlation was observed with the scores for all research questions (Table 3). In women, the correlation was demonstrated only with the scores for the questions about weight loss, food intake amount and subjective assessment of nutritional status; there was no correlation with the scores for the questions about serious health incidents or about the quality of the food intake (dietary restrictions ifany).

"A good nutritional status" was achieved by 33 patients, representing $70.2 \%$ of the total group. A "risk of malnutrition" was found in 13 patients (27.66\% of the total group). The "state of malnutrition" was found in 1 patient $(2.13 \%$ of the total). Fig. 2 displays nutritional status of men and women with ESRD.

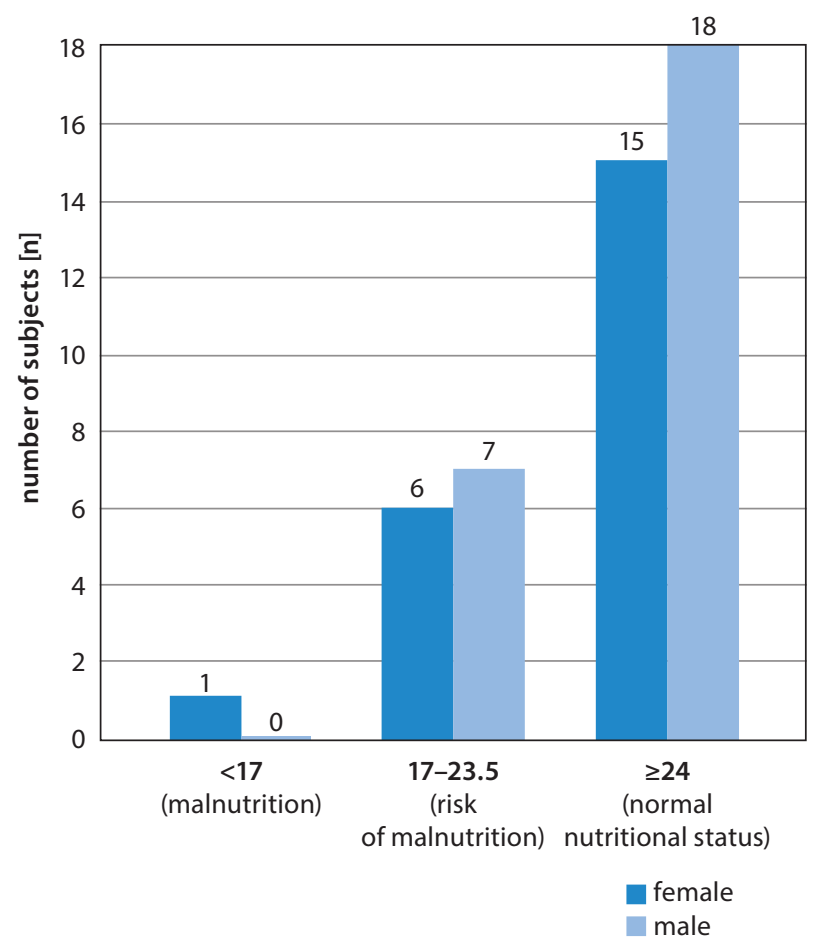

Fig. 2. Nutritional status of men and women with end-stage renal disease (ESRD) (MNA score)
Table 3. Spearman's rank correlation coefficients ( $p$ ) for the final results with selected questions of the minimal nutritional assessment (MNA) scale

\begin{tabular}{|l|c|c|}
\hline \multicolumn{1}{|c|}{ Question } & $\begin{array}{c}\text { Females } \\
(\mathbf{n}=22)\end{array}$ & $\begin{array}{c}\text { Males } \\
(\mathrm{n}=25)\end{array}$ \\
\hline $\begin{array}{l}\text { Has there been a reduction in body mass } \\
\text { in the past 3 months? }\end{array}$ & $0.59^{*}$ & $0.51^{*}$ \\
\hline $\begin{array}{l}\text { Has the patient suffered psychological stress } \\
\text { or acute disease in the past 3 months? }\end{array}$ & 0.36 & $0.48^{*}$ \\
\hline $\begin{array}{l}\text { How many full meals a day does } \\
\text { the patient consume? }\end{array}$ & $0.48^{*}$ & $0.48^{*}$ \\
\hline $\begin{array}{l}\text { Does the patient consume wholesome meals } \\
\text { (dairy products, legumes or eggs, meat, } \\
\text { fish, poultry)? }\end{array}$ & 0.35 & $0.51^{*}$ \\
\hline $\begin{array}{l}\text { Subjective assessment of nutritional status } \\
\text { Sulpes }\end{array}$ & $0.64^{*}$ & $0.58^{*}$ \\
\hline
\end{tabular}

$* p<0.05$

In the question concerning the reduction in body mass in the previous 3 months, $44 \%$ of male subjects and $45.45 \%$ of females reported a loss of 1-3 kg. This may be one of the factors explaining the lower MNA results in men, with no significant associations with the BMI (Table 4).

Table 4. Percentage distribution for scores on the question about weight loss

\begin{tabular}{|l|c|c|c|c|}
\multicolumn{5}{|c|}{ Question b: Weight loss during the last 3 months } \\
\hline F/M [points] & 0 & 1 & 2 & 3 \\
\hline \% females* & 0.00 & 4.6 & 45.4 & 50.00 \\
\hline \% of total** & 0.00 & 2.1 & 21.3 & 23.4 \\
\hline \% males* & 4.0 & 0.0 & 44.0 & 52.0 \\
\hline \% of total** & 2.1 & 0.0 & 23.4 & 27.7 \\
\hline Total \%*** & 2.1 & 2.1 & 44.7 & 51.0 \\
\hline
\end{tabular}

* in relation to female/male group; ${ }^{* *}$ female/male in relation to whole group; ${ }^{* *}$ female and male in relation to whole group of patients.

In the question about serious, stressogenic situations in the previous 3 months (question d), it was observed that as many as $20 \%$ of men reported such an event, while only $4.55 \%$ of women. This may also explain the low values of the final MNA score in men, even in the absence of significant correlations with the BMI (Table 5).

Table 5. Percentage ratio of responses to the question about stress/acute diseases

\begin{tabular}{|l|c|c|}
\hline \multicolumn{2}{|c|}{$\begin{array}{c}\text { Question d: Has the patient suffered psychological stress or acute } \\
\text { disease in the past 3 months? }\end{array}$} \\
\hline \multicolumn{1}{|c|}{ F/M [points] } & 0 & 2 \\
\hline \% females* & 4.5 & 95.5 \\
\hline \% of total** & 2.1 & 44.7 \\
\hline \% males* & 20.0 & 80.0 \\
\hline \% of total** & 10.6 & 42.6 \\
\hline Total \%*** & 12.8 & 87.2 \\
\hline
\end{tabular}

* in relation to female/male group; ${ }^{* *}$ female/male in relation to whole group; ${ }^{* *}$ female and male in relation to whole group of patients. 
Percentage distribution of scores for the question about daily intake of full meals are shown in Table 6.

In the question regarding the number of full meals consumed, the maximum number of points was awarded for eating 3 full meals a day. As many as $40 \%$ of men and $31.82 \%$ of women reported consuming less than 3 full meals a day. Given the significant correlation of the final score with this question, this may provide an explanation for the lower MNA scores of patients with ESRD (Table 6).

Table 6. Percentage distribution of scores for the question about daily intake of full meals

\begin{tabular}{|l|c|c|c|}
\multicolumn{4}{|c|}{ Question j: How many full meals does the patient eat daily? } \\
\hline \multicolumn{1}{|c|}{ F/M [points] } & 0 & 1 & 2 \\
\hline \% females* & 4.6 & 27.3 & 68.2 \\
\hline \% of total** & 2.1 & 12.8 & 31.9 \\
\hline \% males* & 0.0 & 40.0 & 60.0 \\
\hline \% of total** & 0.0 & 21.3 & 31.9 \\
\hline Total \%*** & 2.1 & 34.0 & 63.8 \\
\hline
\end{tabular}

* in relation to female/male group; ${ }^{* *}$ female/male in relation to whole group; ${ }^{* * *}$ female and male in relation to whole group of patients.

In the question regarding the frequency of eating wholesome products, $60 \%$ of men and $45.45 \%$ of women scored the maximum. This means that $40 \%$ of men and $54.54 \%$ of women indicated a limitation in terms of providing the body with wholesome products, which could potentially indicate some dietary restrictions (Table 7).

Table 7. Percentage distribution of scores for the question about eating wholesome products

\begin{tabular}{l|c|c|c|}
\multicolumn{4}{|c}{$\begin{array}{l}\text { Question k: Does the patient consume at least: } 1 \text { dairy product a day; } \\
\text { legumes or eggs } 2 \text { or more times per week; meat, fish or poultry daily? }\end{array}$} \\
\hline F/M [points] & 0 & 0.5 & 1 \\
\hline \% females* & 9.1 & 45.5 & 45.5 \\
\hline \% of total** & 4.3 & 21.3 & 21.3 \\
\hline \% males* & 8.0 & 32.0 & 60.0 \\
\hline$\%$ of total** & 4.3 & 17.0 & 31.9 \\
\hline Total \%*** & 8.5 & 38.3 & 63.2 \\
\hline
\end{tabular}

* in relation to female/male group; ${ }^{* *}$ female/male in relation to whole group; ${ }^{* * *}$ female and male in relation to whole group of patients.

In the question requesting self-assessment of nutritional status, $92 \%$ of men and $77.27 \%$ of women did not express any concern about their nutritional status. However, $8 \%$ of men and $18.18 \%$ of women were not able to give an assessment of their nutritional status, and $4.55 \%$ of women reported a state of malnutrition (Table 8 ).

\section{Discussion}

The medical community, aware of the significance of nutritional status in patient prognosis, has
Table 8. Percentage distribution of scores for the question requesting a subjective assessment of nutritional status

\begin{tabular}{|l|c|c|c|}
\hline \multicolumn{4}{|c|}{ Question o: Self view of nutritional status } \\
\hline \multicolumn{1}{|c|}{ F/M [points] } & 0 & 1 & 2 \\
\hline \% females* & 4.6 & 18.2 & 77.3 \\
\hline \% of total** & 2.1 & 8.5 & 36.8 \\
\hline \% males* & 0.0 & 8.0 & 92.0 \\
\hline \% of total** & 0.0 & 4.3 & 48.9 \\
\hline Total \%*** & 2.1 & 12.8 & 85.1 \\
\hline
\end{tabular}

* in relation to female/male group; ${ }^{* *}$ female/male in relation to whole group; ${ }^{* *}$ female and male in relation to whole group of patients.

demonstrated that malnutrition is associated with increased mortality. ${ }^{5,6,9}$ This fact has even been taken into account in jurisdiction. As of November 8, 2012, an amendment was introduced by the Minister of Health, dated January 1, 2012, introducing an obligation to carry out nutritional status assessment NRS 2002 (Nutritional Risk Screening 2002) or the SGA (Subjective Global Assessment) in each hospital ward, the results of which must accompany the patient disease history. Unfortunately, no such obligation was introduced in outpatient care of clinically stable patients. From the point of view of monitoring patient rehabilitation, a nutritional status assessment should be long-term-oriented and repeated periodically.

Many researchers have tried to evaluate the nutritional status of patients with CKD using dietary questionnaires, anthropometric methods and other techniques. Among dietary questionnaires, the subjective global assessment (SGA) has often been used; its score indicates a positive correlation with the objectively assessed state of nutrition. ${ }^{27-30}$

However, the SGA questionnaire is complex to use, because it requires an extensive physical examination, specifying many anthropometric characteristics.

The MNA scale is used less frequently and takes into account fewer anthropometric factors; however, it has been shown to be just as sensitive in detecting signs of malnutrition as the SGA. ${ }^{31,32}$ The MNA scale is recommended in elderly patients, and it is precisely this group of subjects who represent the largest proportion of dialysis patients worldwide. The largest increase among all patients qualified for the dialysis treatment has been recorded in the 70+ age group. For example, in 2012 in Poland, 64\% of all qualified persons were over 65 years of age.

In this study, all questions in the MNA scale were completed, even if the result in the $1^{\text {st }}$ part of the MNA did not indicate a risk of malnutrition. This allowed the examination of the influence of factors (questions $j$ and $k$ ) related to potential dietary restrictions among patients with ESRD.

Segall et al., in their extensive research using various forms of assessment of nutritional status, showed a strong correlation between malnutrition and risk of mortality in hemodialysis patients (out of 149 patients, 11 patients 
who had obtained a low score in the SGA and for biochemical markers of malnutrition died in the follow-up period). ${ }^{33}$ They also showed a strong correlation between the presence of diabetes and patient survival.

In this study, using the MNA to test nutritional status, there were 13 cases of malnutrition risk (6 women and 7 men) and 1 case of malnutrition. Significant correlations were demonstrated between the MNA score and body weight and the BMI, but only in women. In studies by other authors, such a correlation appeared in both sexes. ${ }^{28}$

In the studies cited above, no correlation was observed between low BMI in men and an MNA score indicative of malnutrition or the risk thereof. This is not surprising, bearing in mind the phenomenon of reverse epidemiology in the population of dialysis patients, i.e., overweight/ obesity predicts lower mortality. ${ }^{34}$

One explanation of this fact could be a negative correlation with the years of renal replacement therapy. On average, women in the examined group were treated with renal replacement therapy for a longer period of time (Table 2), which, considering the changes taking place in the bodies of patients with ESRD, can result in a long-term reduction in body weight and BMI index. ${ }^{5,19}$ The examined group of men were treated for a shorter period of time with renal replacement therapy on average (Table 2); therefore, such significant changes in body weight had not yet taken place; however, the variables not associated with body weight (questions about consumed meals, weight loss and dietary restrictions) did have an impact on the negative MNA result.

A random factor should also be taken into account: the examined group of men was characterized by a higher mean BMI (29.61) and a lower SD of this ratio (4.11). In other words, it was more homogenous compared with the group of women. This could also be a cause of the obtained results.

The influence of the length of time in renal replacement therapy on the MNA result can also be observed in the relationship between the median duration of dialysis (6 years) for the entire study group and the score obtained on the MNA questionnaire. Patients who had been undergoing dialysis for less than 6 years had a mean MNA score of 26.04, classifying their nutritional status as good. For the group that had been undergoing dialysis more than 6 years, the mean MNA score was 23.15, classifying them at risk of malnutrition. Similarly, Koor et al. and Brzosko et al. found a correlation between the duration of dialysis therapy and the risk of malnutrition. ${ }^{28,35}$ The waist-to-hip ratio (WHR) ratio was not statistically significant in any of the groups.

In the abovementioned tests, the influence of factors related to events that may result in changes in body weight, as well as broader eating habits, were also analyzed. It has been shown that the outcome of MNA correlates with the score for the questions concerning weight loss and stressful events in the 3 months prior to the assessment.
According to the authors, the MNA scale shows sensitivity in terms of detecting changes in health, to which patients with ESRD are particularly vulnerable. Patients with ESRD are forced to follow certain dietary restrictions, including the supply of phosphorus..$^{10,18,22}$ The question on the number of full meals (question $j$ in the MNA scale) and the type of food products regularly consumed (question k) may reflect the eating habits of respondents and may be particularly important for patients with ESRD. In our study, a significant correlation between the scores for these questions and the result of the MNA scale was found. This may indicate that patients with ESRD, by following dietary recommendations, can counter-intuitively expose themselves to the risk of malnutrition. Similarly, the score on the question requesting a subjective assessment of the nutritional status correlates with the MNA result, indicating that the patients may actually feel a change in their nourishment status, even when their body weight remains normal. It is the opinion of the authors of this study, based on the reports of other authors, that in such circumstances it is necessary to consult with qualified personnel and perform further assessment of the nutritional status using more sensitive methods. ${ }^{33,35}$

The authors concluded that regular screening tests using the MNA scale can be a useful tool in the course of treatment and rehabilitation of patients with ESRD. Patients with ESRD are regularly weighed before commencing hemodialysis, so the sensitivity of the MNA scale can help in the assessment of adverse changes that may lead to the risk of malnutrition, even when normal body weight is maintained. In the case of negative MNA results, the patient should be immediately referred for more detailed tests to assess their nutritional status.

\section{References}

1. Zhang QL, Rothenbacher D. Prevalence of chronic kidney disease in population-based studies: Systematic review. BMC Public Health. 2008;8:117.

2. Lysaght MJ. Maintenance dialysis population dynamics: Current trends and long-term implications. JAm Soc Nephrol. 2002;13 (Suppl 1):37-40.

3. Król E, Rutkowski B. Przewlekła choroba nerek: Klasyfikacja, epidemiologia i diagnostyka. Forum Nefrologiczne. 2008;1:1-6.

4. Jadeja YP, Kher V. Protein energy wasting in chronic kidney disease: An update with focus on nutritional interventions to improve outcomes. Indian J Endocrinol Metab. 2012;16(2):246-251.

5. Bonanni A, Mannucci I, Verzola D, et al. Protein-energy wasting and mortality in chronic kidney disease. Int J Environ Res Public Health. 2011;8(5):1631-1654.

6. Kovesdy CP, Kalantar-Zadeh K. Why is protein-energy wasting associated with mortality in chronic kidney disease? Semin Nephrol. 2009;29(1):3-14.

7. Modification of Diet in Renal Disease Study Group. The modification of diet in renal disease study: Design, methods and results from the feasibility study. Am J Kidney Dis. 1992;20(1):18-33.

8. Lowrie EG, Lew NL. Death risk in hemodialysis patients: The predictive value of commonly measured variables and an evaluation of death rate differences between facilities. Am J Kidney Dis. 1990;15(5):458-482.

9. Peev V, Nayer A, Contreras G. Dyslipidemia, malnutrition, inflammation, cardiovascular disease and mortality in chronic kidney disease. Curr Opin Lipidol. 2014;25(1):54-60.

10. Toigo G, Aparicio M, Attman P, et al. Expert Working Group report on nutrition in adult patients with renal insufficiency (part 1 of 2). Clin Nutr. 2000;19(3):197-207. 
11. Ikizler TA, Hakim RM. Nutrition in end-stage renal disease. Kidney Int. 1996;50(2):343-357.

12. Leavey SF, Strawderman RL, Jones CA, Port FK, Held PJ. Simple nutritional indicators as independent predictors of mortality in hemodialysis patients. Am J Kidney Dis. 1998;31(6):997-1006.

13. Jiang MY, Hwang JC, Lu YH, Wang CT. Clinical implications and outcome prediction in chronic hemodialysis patients with lower serum potassium ×uric acid product. Eur J Intern Med. 2015;26(8):646-651.

14. Qureshi AR, Alvestrand A, Danielsson A, et al. Factors predicting malnutrition in hemodialysis patients: A cross-sectional study. Kidney Int. 1998;53(3):773-782.

15. Lynch KE, Lynch R, Curhan GC, Brunelli SM. Altered taste perception and nutritional status among hemodialysis patients. J Ren Nutr. 2013;23(4):288-295.

16. Kraut JA, Kurtz I. Metabolic acidosis of CKD: Diagnosis, clinical characteristics, and treatment. Am J Kidney Dis. 2005;45(6):978-993.

17. Ikizler TA, Pupim LB, Brouillette JR, et al. Hemodialysis stimulates muscle and whole body protein loss and alters substrate oxidation. Am J Physiol Endocrinol Metab. 2002;282(1):E107-116.

18. Stenvinkel $P$, Heimbürger $O$, Lindholm B, Kaysen GA, Bergström J. Are there two types of malnutrition in chronic renal failure? Evidence for relationships between malnutrition, infla mmation and atherosclerosis (MIA syndrome). Nephrol Dial Transplant. 2000;15(7):953-960.

19. Kraut JA, Madias NE. Metabolic acidosis of CKD: An update. Am J Kidney Dis. 2016;67(2):307-317.

20. Movilli E, Bossini N, Viola BF, et al. Evidence for an independent role of metabolic acidosis on nutritional status in hemodialysis patients. Nephrol Dial Transplant. 1998;13:674-678.

21. Ballmer PE, McNurlan MA, Hulter HN, Anderson SE, Garlick PJ, Krapf R. Chronic metabolic acidosis decreases albumin synthesis and induces negative nitrogen balance in humans. JClin Invest. 1995;95(1):39-45.

22. Fouque $D$, Laville M. Low protein diets for chronic kidney disease in non-diabetic adults. Cochrane Database Syst Rev. 2009;8(3):6-8.

23. Green SM, Watson R. Nutritional screening and assessment tools for older adults: Literature review. J Adv Nurs. 2006;54(4):477-490.

24. Guigoz Y. The Mini Nutritional Assessment (MNA) review of the literature: What does it tell us? J Nutr Health Aging. 2006;10(6):466-485.
25. Vellas B, Guigoz Y, Garry PJ, et al. The Mini Nutritional Assessment (MNA) and its use in grading the nutritional state of elderly patients. Nutrition. 1999;15(2):116-122.

26. Burman M, Säätelä S, Carlsson M, Olofsson B, Gustafson Y, Hörnsten $C$. Body mass index, mini nutritional assessment, and their association with five-year mortality in very old people. J Nutr Health Aging. 2015;19:461-467.

27. Kondrup J, Allison SP, Elia M, Vellas B, Plauth M. ESPEN guidelines for nutrition screening 2002. Clin Nutr. 2003;22:415-421.

28. Koor BE, Nakhaie MR, Babaie S. Nutritional assessment and its correlation with anthropometric measurements in hemodialysis patients. Saudi J Kidney Dis Transpl. 2015;26(4):697-701.

29. Steiber A, Leon JB, Secker D, et al. Multicenter study of the validity and reliability of subjective global assessment in the hemodialysis population. J Ren Nutr. 2007;17(5):336-342.

30. Tan SK, Loh YH, Choong LH, Suhail SM. Subjective global assessment for nutritional assessment of hospitalized patients requiring hemodialysis: A prospective cohort study. Nephrology (Carlton). 2016;21(11):944-949.

31. Santin FG, Bigogno FG, Dias Rodrigues JC, Cuppari L, Avesani CM. Concurrent and predictive validity of composite methods to assess nutritional status in older adults on hemodialysis. J Ren Nutr. 2016;26(1):18-25.

32. Tsai AC, Wang JY, Chang TL, Li TY. A comparison of the full Mini Nutritional Assessment, short-form Mini Nutritional Assessment, and Subjective Global Assessment to predict the risk of protein-energy malnutrition in patients on peritoneal dialysis: A cross-sectional study. Int J Nurs Stud. 2013;50(1):83-89.

33. Segall L, Mardare NG, Ungureanu S, et al. Nutritional status evaluation and survival in hemodialysis patients in one center from Romania. Nephrol Dial Transplant. 2009;24(8):2536-2540.

34. Ladhani M, Craig JC, Irving M, Clayton PA, Wong G. Obesity and the risk of cardiovascular and all-cause mortality in chronic kidney disease: A systematic review and meta-analysis. Nephrol Dial Transplant. 2017;32(3):439-449.

35. Brzosko S, Hryszko T, Kłopotowski M, Myśliwiec M. Validation of Mini Nutritional Assessment scale in peritoneal dialysis patients. Arch Med Sci. 2013;9(4):669-676. 